\title{
Mechanical Behaviour of Yttria- and Ferric Oxide-Doped Zirconia at Different Temperatures
}

\author{
G. A. Gogotsi \\ Institute for Problems of Strength, National Academy of Sciences of Ukraine, 2 Timiryazevskaya Str., 252014 Kiev, Ukraine
}

(Received 18 October 1996; accepted 8 July 1997)

\begin{abstract}
The variation of strengh, deformability, fracture toughness and other characteristics of partially stabilized zirconia ceramics (Y-Fe-PSZ) doped with $3 \%$ yttrium and $3 \%$ ferric oxide over a temperature range from -140 to $1400^{\circ} \mathrm{C}$ were investigated. Fracture toughness $\left(K_{1 c}\right)$ values obtained by the methods such as SENB, SEPB, IS and IF were compared. Lower temperatures resulted in an increase in fracture toughness by approximately $29 \%$. Using the Vickers indents as stress concentrators for the IS tests we derived the relationship between $K_{1 c}$ values and mean values of radial crack length described by a second-degree polynomial. The data for zirconia (Y-PSZ and Mg-PSZ) and silicon-nitride ceramics, as well as the fractographic data, were used to analyse the results. It was established that the addition of ferric oxide exerted a positive effect on the strengh and fracture toughness of zirconia ceramics. (C) 1998 Elsevier Science Limited and Techna S.r.l.
\end{abstract}

\section{INTRODUCTION}

As single crystals transformation-toughened zirconia-based ceramics stabilised with yttria are usually linear elastic and those stabilised with magnia and ceria are usually inelastic at room temperature. ${ }^{1}$ This gives rise ${ }^{2}$ to other differences in their behaviour on loading. However, the mechanical behaviour was mainly studied on the materials characterised with considerable inelasticity ${ }^{3-5}$ while the materials with the limit of proportionality not greatly differing from the ultimate strength were given little attention. Since any possible inelasticity can affect the evaluation of real performance of ceramics, Y-PSZ with the addition of ferric oxide somewhat changing their mechanical behaviour were used for the investigation.

\section{MATERIALS AND METHODS}

The ceramics under study were produced by slipcast molding followed by isostatic pressing at 2 kbars and sintering. Besides $\mathrm{ZrO}_{2}$ of technical purity, they contained $3 \% \mathrm{Y}_{2} \mathrm{O}_{2}$ and $3 \% \mathrm{~F}_{2} \mathrm{O}_{3}$ (see Ref. 6 for more detailed information).

To compile additional information for the data analysis, we also studied other materials (Table 1). In particular we tested conventional partially stabilised ceramics Y-PSZ produced almost in the same way as the above, ${ }^{6}$ tetragonal polycrystalline ceramics Y-TZP prepared by EMPA (Switzerland), their fracture toughness being tested room temperature (RT), ${ }^{7}$ and partially stabilised ceramics Mg-PSZ of TS-grade made by Nilcra Ceramics (Australia), being investigated at low temperatures (LT). ${ }^{8}$ We also used Y-PSZ crystals (of the same composition as Y-PSZ-C) prepared by the Institute of General Physics of Russian Academy of Sciences, ${ }^{9}$ comparatively uniform reactionbonded $\left(\mathrm{Si}_{3} \mathrm{~N}_{4}-\mathrm{RB}^{10}\right)$ and hot-isostatically-pressed $\left(\mathrm{Si}_{3} \mathrm{~N}_{4}-\mathrm{HIP}^{11}\right)$ silicon nitride ceramics.

Rectangular beam specimens were prepared from the blanks and ground with diamond tools, their edges being rounded. To prepare the specimens for flexural fracture toughness tests, three stress 
Table 1. Materials for additional tests

\begin{tabular}{|c|c|c|c|c|c|}
\hline Materials & Index & Additives (\%) & $\begin{array}{c}\text { Brittleness measure, } \\
\chi \chi\end{array}$ & $\begin{array}{l}\text { Flexural strength, } \\
\qquad S(\mathrm{MPa})\end{array}$ & $\begin{array}{c}\text { Modulus of elasticity, } \\
E(\mathrm{GPa})\end{array}$ \\
\hline Y-TZP & TZP & $\mathrm{Y}_{2} \mathrm{O}_{3}(3)$ & 1 & 774 & 211 \\
\hline Y-PSZ & PSZ & $\mathrm{Y}_{2} \mathrm{O}_{3}(3)$ & 1 & 425 & 197 \\
\hline Y-PSZ-C & $\mathrm{C}$ & $\mathrm{Y}_{2} \mathrm{O}_{3}(3)$ & 1 & 506 & 297 \\
\hline Mg-PSZ & $\mathrm{Mg}$ & $\mathrm{MgO}(9)$ & 0.46 & 641 & 207 \\
\hline $\mathrm{Si}_{3} \mathrm{~N}_{4}-\mathrm{RB}$ & S-RB & $\mathrm{SiC}_{,}(30)$ & 1 & 165 & 178 \\
\hline $\mathrm{Si}_{3} \mathrm{~N}_{4}-\mathrm{IP}$ & $\mathrm{S}-\mathrm{HP}$ & $\mathrm{Y}_{2} \mathrm{O}_{3}(4)$ & 1 & 658 & 314 \\
\hline
\end{tabular}

concentrators were applied on to the surface along their axis. Therefore, in these cases the experimental points possess double designation the first part of which is the specimen number and the second one is the index of stress concentrator location. For indentation tests the fragments of these specimens were used. To study the indenter impressions and to observe the crack development, the sides of the specimen were polished with diamond paste.

The investigations were mainly based on our procedures for specimen testing at different temperatures. ${ }^{12}$ In accordance with them the displacement of specimens $(\delta)$ and the applied loads $(\mathrm{P})$ were measured on 4-point flexure (Fig. 1). For this purpose we used experimental loading modules mounted on conventional test machines. The $\delta$ values were measured by LVTD with a sensitivity of $\pm 0.1 \mu \mathrm{m}$, the specimens were cooled under liquid nitrogen vapors. The loading module for RT indentation tests was equipped with the Vickers indenter and the 2-co-ordinate support table.

The inelasticity of ceramics was estimated by their brittleness measure $\chi^{2}$ which is equal to the ratio of the specific elastic energy accumulated in the material by the moment of its fracture to the total specific energy spent for its deformation by the same moment:

$$
\chi=\sigma_{u}^{2} / 2 E \int_{0}^{\varepsilon_{u}} \varepsilon
$$

where $\sigma_{u}$ is the ultimate strength, $E$ is the elasticity modulus, $\varepsilon_{u}$ is the ultimate strain and $\sigma$ is the stress at current strain values $\varepsilon$. For elastic materials the flexural strengths were calculated by the conventional equation of applied mechanics: ${ }^{13}$

$$
S=\frac{3 s}{b h^{2}} P
$$

For inelastic materials Nadai's equation ${ }^{14}$ was used (for designations see Fig. 1(b):

$$
\sigma=\frac{2 s}{b h^{2}}\left(P+\frac{}{2 d \delta}\right)
$$

The $\varepsilon$ values were determined as

$$
\varepsilon=\frac{4 h}{L^{2}} \delta
$$

To calculate the ultimate strength $\sigma_{u}$ and the ultimate strain $\varepsilon_{u}$, the ultimate values of $P$ and $\delta$ were substituted into (3) and (4), respectively.

The fracture toughness results were obtained by several competing procedures (Table 2): by the simplest and widely used method (SENB); by the method which appears to be the most reliable (SEPB), by the method characterised by a simple preparation of stress concentrators (IS); and by the method requiring a small amount of test materials (IF).

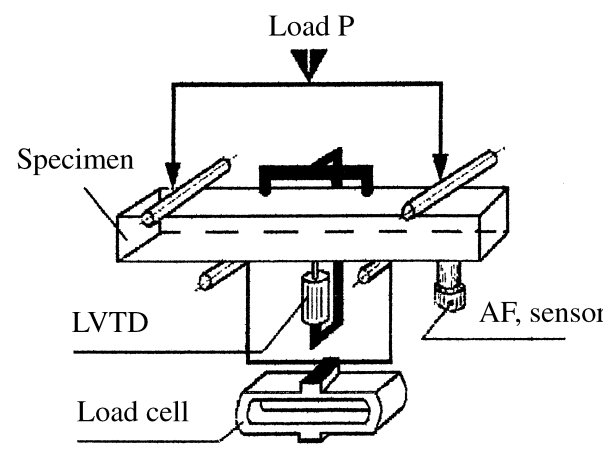

(a)

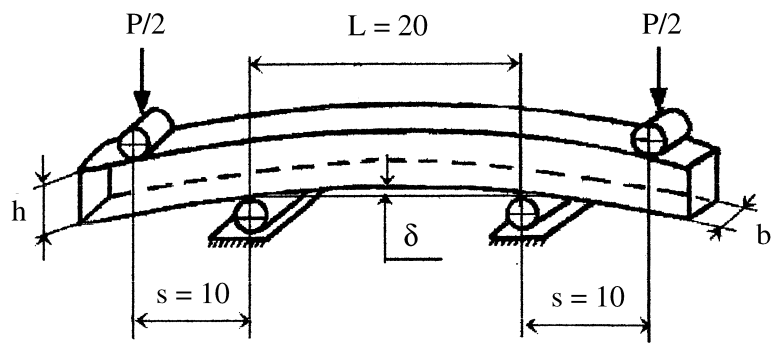

(b)

Fig. 1. (a) Ceramtest-type loading module for flexural tests (strength, fracture toughness, deformability, acoustic-emission and elasticity) of ceramics at RT and (b) schematic drawing of a specimen for the strength test. 
Table 2. Test methods

\begin{tabular}{|c|c|c|c|}
\hline Method \\
Single edge notched beam \\
SENB \\
Single edge precracked beam \\
SEPB \\
Indentation strength \\
IS
\end{tabular}

SENB and SEPB test results were processed as usual by: ${ }^{15}$

$$
K_{1 c}^{2}=\frac{3 L P}{2 h b^{2}} l^{0.5} F(\alpha) .
$$

Here

$$
\begin{gathered}
a=/ / b, \\
F(\alpha)=\frac{1.99-\alpha(1-\alpha)(2.15-3.93 \alpha-2.7 \alpha)}{(1+2 \alpha)(1-\alpha)^{1.5}}
\end{gathered}
$$

IS fracture toughness was determined according to ${ }^{16}$

$$
K_{1 c}=\eta\left(E / H_{V}\right)^{1.8}\left(S_{i} Q^{1 / 3}\right)^{3 / 4}
$$

Here $\eta=0.59, H_{V}$ is the Vickers hardness, $Q$ is the indentation load, and $S_{i}$ is the flexural strength of the specimen with the impression.
In the IF method the $K_{V}$ values ( $K_{V}$ is defined as an approximation of $K_{1 c}$ for the IF-method ) were determined by: ${ }^{17}$

$$
K_{v_{1}}=0.036 E^{0.4} Q^{0.6} a^{0.8} c^{-1.5}
$$

But since ${ }^{17}$ is designed for the cases of median cracks formed under the Vickers indenter (until now we revealed them in $\mathrm{ZrO}_{2}$ materials only in cubic single crystals), the equation ${ }^{18}$ for the Palmqvist crack was also applied:

$$
K_{v_{2}}=0.018 H_{V}\left(E / H_{V}\right)^{0.4} a^{0.5}\left(\frac{c-a}{a}\right)^{0.5}
$$

\begin{tabular}{|c|c|c|c|c|c|c|c|}
\hline \multirow[t]{2}{*}{ Sintered temperature $\left({ }^{\circ} \mathrm{C}\right)$} & \multicolumn{7}{|c|}{ Test temperature $\left({ }^{\circ} \mathrm{C}\right)$} \\
\hline & $\chi$ & $\begin{array}{c}\mathrm{AT} \\
S(\mathrm{MPa})\end{array}$ & $K_{1 c}\left(\mathrm{MPa} \mathrm{m}^{1 / 2}\right)$ & $S(\mathrm{MPa})$ & $\begin{array}{l}800 \\
K_{1 c}\left(\mathrm{MPa} \mathrm{m}^{1 / 2}\right)\end{array}$ & $S(\mathrm{MPa})$ & $\begin{array}{l}1200 \\
K_{1 c}\left(\mathrm{MPa} \mathrm{m}^{1 / 2}\right)\end{array}$ \\
\hline 1320 & 0.99 & 812 & 10.9 & 308 & 4.3 & - & - \\
\hline 1330 & 0.94 & 859 & 8.8 & 237 & 3.5 & - & - \\
\hline 1340 & 0.88 & 977 & 13.3 & 303 & 5.5 & 207 & 2.3 \\
\hline 1350 & 0.95 & 786 & 12.0 & 217 & 3.3 & 120 & 2.9 \\
\hline
\end{tabular}

\section{RESULTS}

$\mathrm{Fe}_{2} \mathrm{O}_{3}$-doped ceramics sintered at different temperatures (Table 3) were tested on 3-point flexure

Table 3. Test results for $\mathrm{ZrO}_{2}$-ceramics with $\mathrm{Y}_{2} \mathrm{O}_{3}$ and $\mathrm{Fe}_{2} \mathrm{O}_{3}$ 
(40 mm span). It was established that at $1200^{\circ} \mathrm{C}$ or higher they exhibited considerable creep (crosshead speed was $0.5 \mathrm{~mm} \mathrm{~min}^{-1}$ ). Proceeding from the data obtained, ceramics sintered at $1340^{\circ} \mathrm{C}$ were chosen as optimum ones, they were designated $\mathrm{Y}_{-}$ $\mathrm{Fe}-\mathrm{PSZ}$ ("Fe" is the index for Fig. 2) and investigated at RT and LT. The results of their strength determinations (eqns (2) and (3)) at RT on 4-point flexure (20-40 $\mathrm{mm}$ span) are summarised in Table 4. Fracture toughness results (eqns (5) and (6)) on 3point flexure $(20 \mathrm{~mm}$ span) are depicted in Fig. 2, the data for other materials are also presented for comparison. The $K_{v}$ values (eqns (7) and (8)) as a function of the load applied to the indenter are demonstrated in Fig. 3.

\section{DISCUSSION}

Data in Table 4 show that $\mathrm{Y}-\mathrm{Fe}-\mathrm{PSZ}$ displays not only the scatter of strength values which is usually taken into account, but also that of the brittleness measure.

The analysis of Fig. 2 reveals a growth of fracture toughness with a fall of test temperature both for the ceramics under study and for other ceramics and single crystals with $\mathrm{Y}_{2} \mathrm{O}_{3}$. In this case the $\mathrm{S}$ value for $\mathrm{Y}-\mathrm{Fe}-\mathrm{PSZ}$ ceramics increased up to $917 \mathrm{MPa}$. On the whole these data do not contradict other results of Refs $1,8,19$. At the same time the fracture toughness of values for $\mathrm{Si}_{3} \mathrm{~N}_{4}$ ceramics (S-HP and $\mathrm{S}-\mathrm{RB}$ in Fig. 2) remained practically unchanged under such conditions.

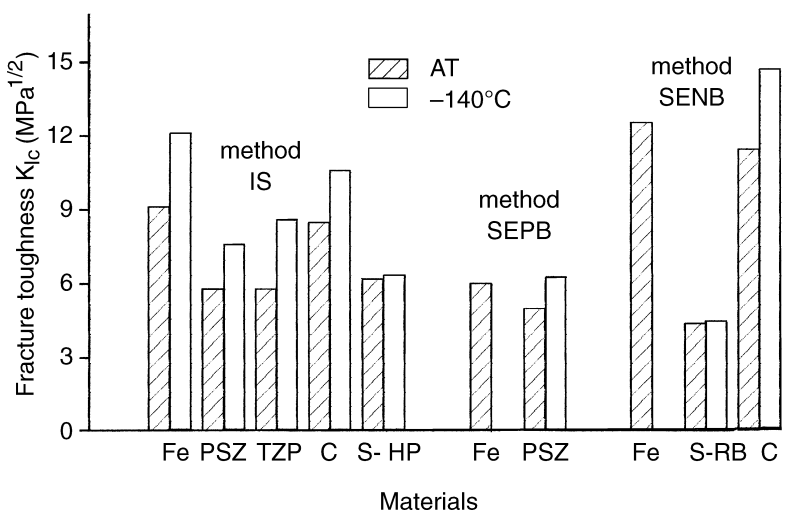

Fig. 2. Results of comparative fracture toughness tests at RT and $-140^{\circ} \mathrm{C}$.

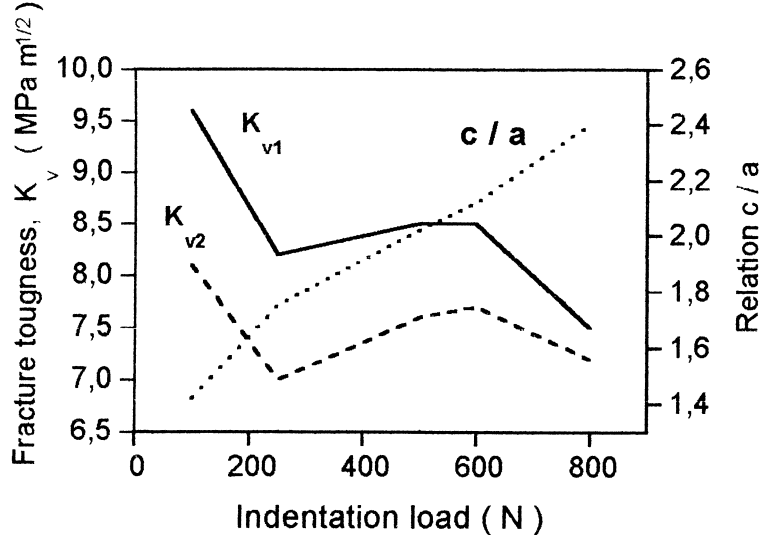

Fig. 3. Fracture toughness and $c / a$ relation for $\mathrm{Y}-\mathrm{Fe}-\mathrm{PSZ}$ on the Vickers indentation.

Inelastic ceramics $\mathrm{Mg}-\mathrm{PSZ}$ exhibited an increase and then a decrease of their $K_{1 c}$-values (Fig. 4) with lower test temperatures. This effect (see also Ref. 8) was observed in the temperature range of a considerable inelasticity decrease (in Fig. 4 it is shown as a change of the brittleness measure $\chi$ ) for these ceramics in the zone of their first low temperature elastic-inelastic transition.

During the $K_{1 c}$ calculations of values based on SEPB data (eqn (4)) one could pay attention to a considerable dependence (Table 5) of the results on the methods of determining the crack length which were as follows: (i) compliance data for the specimen with a crack; (ii) mean values of crack lengths on both sides of the specimen or (iii) measurements (ASTM E-39920) on the fracture surface of the specimen (Fig. 5). If we compare IS and SEPB fracture toughness data (Fig. 2 and Table 5), the result corresponding to the third method appear to be the closest ones. It should be noticed that just this method is recommended, e.g. in Refs 21, 22. Unfortunately, we could hardly overcome (and not always) technical problems associated with measurements on fracture surfaces which also took place in. ${ }^{21}$

The data of Table 5 are also interesting because they, for instance, explain the difference in the shape of R-curves ${ }^{23}$ plotted by methods (i) and (ii) and generally point to the significance of such curves obtained by the method (i) on flexure.

A detailed consideration of IS fracture toughness data for Y-Fe-PSZ ceramics (Table 6) can hardly

Table 4. Test results for $\mathrm{Y}-\mathrm{Fe}-\mathrm{PSZ}$ ceramics at $\mathrm{RT}$ (4-point flexure)

\begin{tabular}{lcccccccccc}
\hline & 35 & 41 & 37 & 45 & 39 & 44 & 40 & 46 & Average & SD \\
\hline$\chi$ & 0.7 & 0.82 & 0.86 & 0.92 & 0.93 & 0.96 & 1 & 1 & 0.88 & 0.1 \\
$\sigma_{\mathrm{u}}(\mathrm{MPa})$ & 760 & 767 & 673 & 637 & 717 & 791 & 638 & 765 & 711 & 62 \\
$\varepsilon_{u} 10^{-4}\left(\mathrm{~m} \mathrm{~m}^{-1}\right)$ & 45.9 & 42.0 & 41.1 & 35.7 & 38.0 & 42.9 & 33.1 & 40.2 & 39.9 & 4.1 \\
$S(\mathrm{MPa})$ & 866 & 811 & 698 & 658 & 732 & 797 & 638 & 765 & 746 & 79 \\
$E(\mathrm{GPa})$ & 203 & 196 & 181 & 188 & 196 & 189 & 193 & 190 & 192 & 7 \\
\hline
\end{tabular}




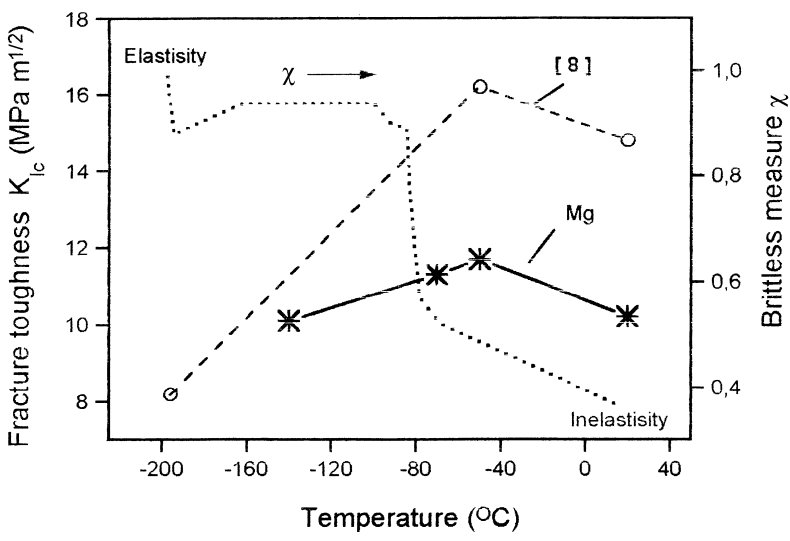

Fig. 4. Fracture toughness variation for $\mathrm{Mg}-\mathrm{PSZ}$ ceramics in the temperature range of inelastic-elastic transition.

reveal any unambiguous dependence between $K_{1 c}$ values and crack lengths $c$ formed on the indentation of the specimen. Taking into account the observation of the authors of this method ${ }^{16}$ that a certain change in the length of such cracks did not exert a noticeable influence on the values of $K_{1 c}$ and remaining within the Griffith theory, we assumed the following: if in our case the geometric parameters of loading are constant and the distribution of acting stresses in the specimen is the same, the beginning of uncontrolled fracture of every material is determined by its own critical crack length $l_{c r}$. Thus, an initial crack $c$ of any length should develop up to the $l_{c r}$ value during the flexural loading of the specimen. Therefore, there are no grounds to consider (see in Ref. 21 for observations of different authors on this problem) that such heterogeneous ceramics as $\mathrm{Y}-\mathrm{Fe}-\mathrm{PSZ}$ should display an increase of 2.52 times, as it was shown in Ref. 16 and confirmed in Ref. 24. The fact that every material is characterised by its own behaviour of subcritical crack (c) growth is also confirmed by the differences

Table 5. Effect of crack length measurement procedure on $K_{1 c}$ values (SEPB)

\begin{tabular}{lccccc}
\hline \multicolumn{2}{c}{ (i) Method } & \multicolumn{2}{c}{ (ii) Method } & \multicolumn{2}{c}{ (iii) Method } \\
\hline $\begin{array}{c}\text { I } \\
(\mathrm{mm})\end{array}$ & $\begin{array}{c}K_{1 c} \\
\left(\mathrm{MPa} \mathrm{m}^{1 / 2}\right)\end{array}$ & $\begin{array}{c}\text { I } \\
(\mathrm{mm})\end{array}$ & $\begin{array}{c}K_{1 c} \\
\left(\mathrm{MPa} \mathrm{m}^{1 / 2}\right)\end{array}$ & $\begin{array}{c}\text { I } \\
(\mathrm{mm})\end{array}$ & $\begin{array}{c}K_{1 c} \\
\left(\mathrm{MPa} \mathrm{m}^{1 / 2}\right)\end{array}$ \\
\hline Y-Fe-PSZ & & & & & \\
2.31 & 2.1 & 2.79 & 3.2 & 3.09 & 4.5 \\
3.01 & 4.7 & 3.0 & 5.0 & 3.34 & 7.4 \\
3.24 & 4.7 & 3.0 & 3.2 & 3.41 & 6.1 \\
3.52 & 5.4 & - & - & 3.71 & 6.9 \\
Y-PSZ & & & & & \\
2.91 & 3.8 & 2.96 & 4.0 & 3.17 & 5.0 \\
- & - & 2.77 & 5.3 & 2.9 & 6.6 \\
- & - & 2.77 & 5.3 & 3.0 & 5.8 \\
Mg-PSZ & & & & & \\
2.22 & 9.5 & 2.33 & 10.2 & 2.60 & 12.0 \\
2.23 & 9.8 & 2.51 & 11.6 & 2.55 & 11.9 \\
\hline
\end{tabular}

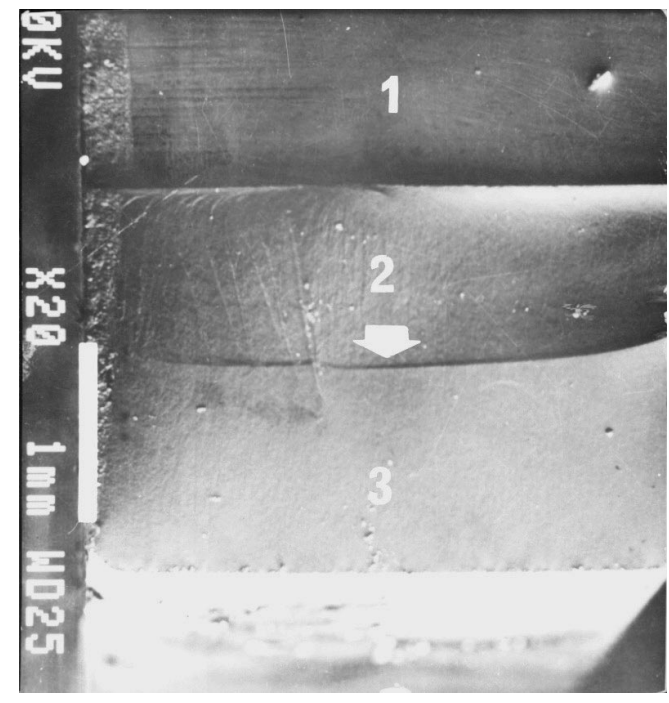

Fig. 5. Fracture surface of the specimen (SEPB method): 1 saw notch, 2 - precrack front, 3 - fast fracture region.

in prefracture zones on load-displacement curves for the IS specimens (Fig. 6).

Having no possibility to make direct measurements confirming the above, we tried to find a characteristic associated with $l_{c r}$. As the first approach, we used an averaged crack length near the indenter impressions $\left(c_{a v}\right.$ in Table 6$)$ specific for each specimen. For its determination on each fragment of IS specimens tested at a load of $500 \mathrm{~N}, 12$ impressions were made. The curves were plotted with $c_{a v}$ value (Fig. 7); they are described by seconddegree polynomial the coefficients of which coincide in rough approximation for $\mathrm{RT}$ and $-140^{\circ} \mathrm{C}$.

As opposed to the above, the results of similar Y-PSZ tests (Table 7) did not reveal any specific features.

Table 6. Test results for Y-Fe-PSZ ceramics method)

\begin{tabular}{|c|c|c|c|c|c|}
\hline \multirow{3}{*}{$\begin{array}{l}\text { Specimen } \\
\text { (no./index) }\end{array}$} & \multicolumn{5}{|c|}{ Test temperature $\left({ }^{\circ} \mathrm{C}\right)$} \\
\hline & \multicolumn{2}{|l|}{ AO } & \multicolumn{2}{|l|}{-140} & \multirow[b]{2}{*}{$\begin{array}{l}\mathrm{C}_{\mathrm{av}} \\
(\mu \mathrm{m})\end{array}$} \\
\hline & $\begin{array}{c}K_{1 c} \\
\left(\mathrm{MPam}^{1 / 2}\right)\end{array}$ & $\begin{array}{c}\mathrm{C} \\
(\mu \mathrm{m})\end{array}$ & $\begin{array}{c}K_{1 c} \\
\left(\mathrm{MPam}^{1 / 2}\right)\end{array}$ & $\begin{array}{c}\mathrm{c} \\
(\mu \mathrm{m})\end{array}$ & \\
\hline $23 / 1$ & 7.9 & 338 & - & - & \\
\hline$/ 2$ & - & - & 10.4 & 337 & 348 \\
\hline /3 & - & - & 10.5 & 339 & \\
\hline $24 / 2$ & - & - & 14.9 & 262 & \\
\hline$/ 3$ & 11.6 & 260 & - & - & 266 \\
\hline $25 / 2$ & - & - & 15.2 & 278 & \\
\hline$/ 3$ & - & - & 13.7 & 241 & 278 \\
\hline $64 / 2$ & - & - & 12.2 & 295 & \\
\hline$/ 3$ & 8.7 & 305 & - & - & 298 \\
\hline $66 / 1$ & - & - & 10.2 & 334 & \\
\hline$/ 2$ & 8.3 & 331 & - & - & 312 \\
\hline$/ 3$ & - & - & 11.3 & 289 & \\
\hline 69/1 & 8.6 & 258 & - & - & \\
\hline$/ 2$ & - & - & 11.5 & 264 & 297 \\
\hline 70/1 & 9.4 & 271 & - & - & \\
\hline$/ 2$ & - & - & 12.2 & 267 & 283 \\
\hline
\end{tabular}




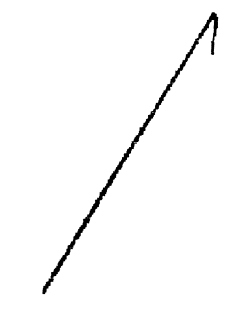

Y-Fe-PSZ

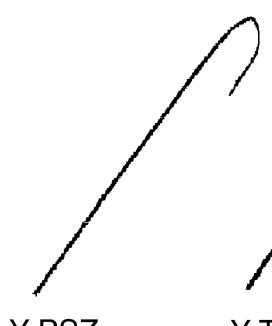

Y-PSZ
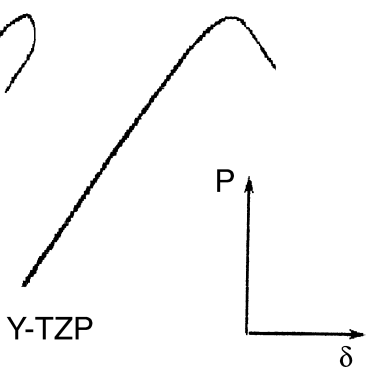

Fig. 6. Final sections of prefracture zones on load-displacement curves for the IS-tested specimens of different ceramics.

The tests by the IS method show that Y-Fe-PSZ ceramics (data were obtained on other series of specimens) exhibit lower $K_{1 c}$ values with an increase in indentation loads. Thus at 100, 250 and $500 \mathrm{~N}$ loads they were equal to $11.07,11.1$ and 9.95 $\mathrm{MPa} \mathrm{m}^{1 / 2}$, respectively. For Y-PSZ the picture is approximately the same, their $K_{1 c}$ values were 6.1 , 5.8 and $5.8 \mathrm{MPa} \mathrm{m}^{1 / 2}$, respectively.

Considering these unusual results, we tried to verify the reliability of the test method used. For this purpose $\mathrm{Y}-\mathrm{TZP}$ ceramics and the test data of Ref. 7 were employed. A certain agreement between our data and the data by other authors was established (Table 8).

The analysis of IF data (Fig. 3) has demonstrated that higher indentation loads result in lower

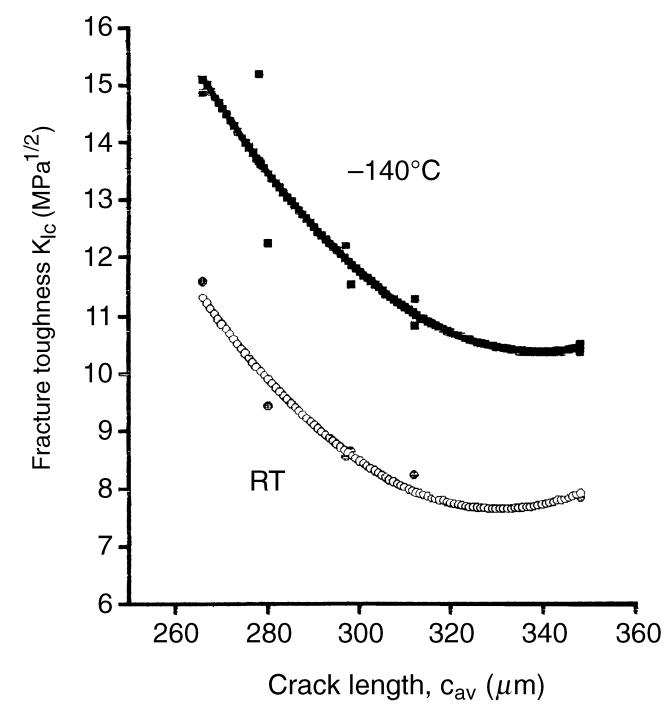

Fig. 7. $K_{1 c}$ values for $\mathrm{Y}-\mathrm{Fe}-\mathrm{PSZ}$ ceramics as a function of average crack lengths near the indenter impression (IS method).

Table 7. Test results for Y-PSZ ceramic (IS method)

\begin{tabular}{lllllll}
\hline $\begin{array}{l}\text { Specimens } \\
\text { (no./index) }\end{array}$ & $8 / 3$ & $6 / 3$ & $3 / 3$ & $7 / 3$ & $5 / 3$ & $13 / 3$ \\
\hline$K_{1 c}\left(\mathrm{MPa} \mathrm{m}^{1 / 2}\right)$ & 5.95 & 5.95 & 5.81 & 5.77 & 5.75 & 5.62 \\
$c(\mu \mathrm{m})$ & 4.00 & 4.11 & 4.35 & 4.24 & 4.17 & 4.28 \\
$c_{a v}(\mu \mathrm{m})$ & 4.10 & 4.12 & 4.35 & 4.11 & 4.08 & 4.24 \\
\hline
\end{tabular}

$K_{v}$ values. They also differ considerably depending on the equation applied for calculations. It is typical that in all the cases of indentation only Palmqvist cracks were formed in the specimens (Fig. 8(a)). For $\mathrm{Y}-\mathrm{Fe}-\mathrm{PSZ}$ ceramics the ratio of $c / a$ achieved 2.3 (usual condition of validity of applying eqn (7) at loads close to those inducing the failure of indenter impressions (Fig. 8(b)). It is interesting that similar failure of indenter impressions was earlier observed also in the tests of $\mathrm{ZrO}_{2}$ PSZ crystals. ${ }^{19} \mathrm{It}$ appears, e.g. that the ceramics under study do not meet the requirements set forth in Ref. 22, only when they meet them, their fracture toughness can

Table 8. Fracture toughness results for Y-TZP ceramics

\begin{tabular}{lcccc}
\hline Test method & & IS & & $\begin{array}{c}\text { Chevron } \\
\text { notched } \\
\text { beam } \\
\text { method }\end{array}$ \\
\hline No. of specimens & 4 & 3 & 4 & 4 \\
$K_{1 c}\left(\mathrm{MPa} \mathrm{m}^{1 / 2}\right)$ & 5.67 & 5.82 & 5.61 & 5 \\
$\mathrm{SD}\left(\mathrm{MPam}^{1 / 2}\right)$ & 0.38 & 0.1 & 0.09 & 0.27 \\
Indentation load (Q) & 100 & 500 & - & - \\
Investigators & IPP & IPP & EMPA $^{7}$ & $\mathrm{ESN}^{7}$ \\
\hline
\end{tabular}

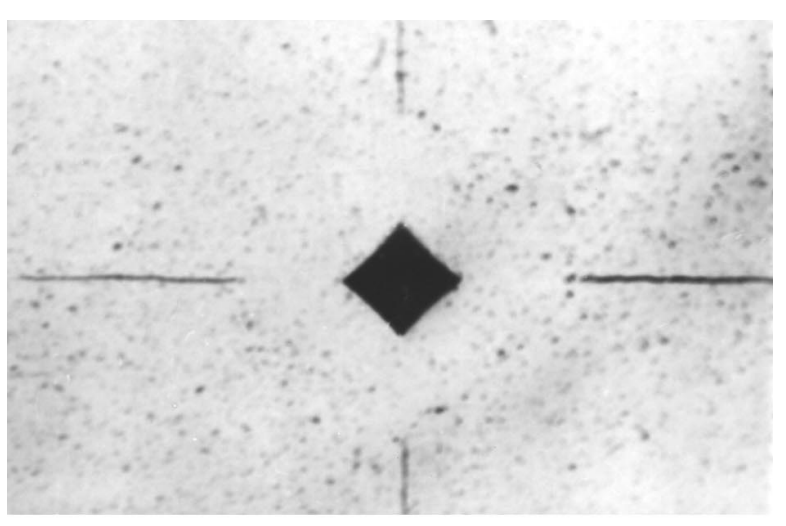

(a)

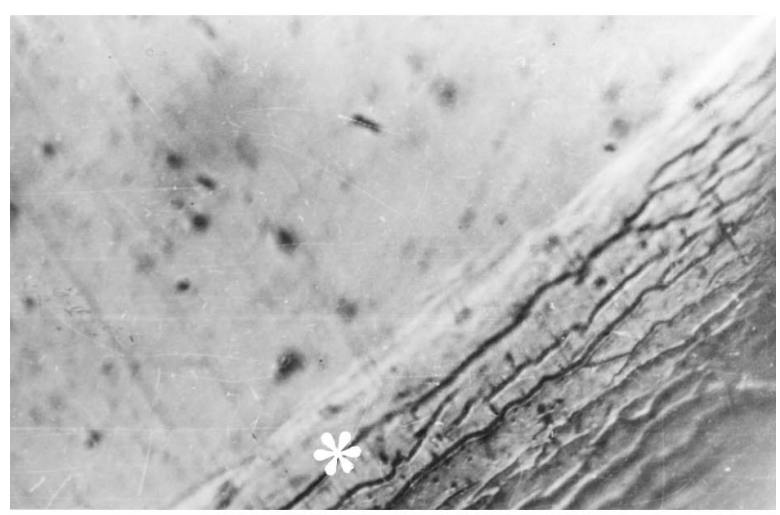

(b)

Fig. 8. Indentation results for $\mathrm{Y}-\mathrm{Fe}-\mathrm{PSZ}$ specimens: (a) radial crack pattern near the impression (surface layer is ground-off) at $500 \mathrm{~N}$; (b) fracture zone of the impression at $800 \mathrm{~N}$ (* surface of impression). 
reliably be evaluated by the IF method. It should be noted that the use of eqn (8) does not introduce any specific features in the unambiguity of data obtained by different test methods.

\section{CONCLUSIONS}

We investigated the variation of strength, deformability, fracture toughness and other characteristics of partially stabilised zirconia ceramics ( $\mathrm{Y}-\mathrm{Fe}-$ PSZ) doped with $3 \%$ yttrium and $3 \%$ ferric oxide over a temperature range from -140 to $1400^{\circ} \mathrm{C}$. Fracture toughened $\left(K_{1 c}\right)$ values obtained by such methods as SENB, SEPB, IS and IF were compared. Lower temperatures resulted in an increase in fracture toughness by $29 \%$ approximately. For the IS test the Vickers indents used as stress concentrators we derived the relationship between $K_{1 c}$ values and mean value of radial cracks length described by a second-degree polynomial. It was demonstrated that for the SEPB-method $K_{1 c}$ values were strongly dependent on a procedure of measuring the crack initial length. The data for zirconia (Y-PSZ and $\mathrm{Mg}-\mathrm{PSZ}$ ) and silicone-nitride ceramics as well as fractographic ones were used to analyse the results.

It was established that the addition of ferric oxide exerted a positive effect on the strength and fracture toughness of $\mathrm{Y}-\mathrm{Fe}-\mathrm{PSZ}$ ceramics. This is associated with a decrease of brittleness caused by their relative inelastisity.

\section{ACKNOWLEDGEMENTS}

Some of the materials studied were kindly supplied by S. Yu. Pliner, G. D. Quinn and M. V. Swain.

\section{REFERENCES}

1. GOGOTSI, G. A. \& SWAIN, M. V., Comparison of strength and fracture toughness single and polycrystalline zirconia. In Science and Technology of Zirconia V, ed. S. D. S. Badwal, M. J. Bannister, R. H. J. Hannik. Technomic Publishing Co. Inc., Lancaster-Basel, 1993, pp. 347-359.

2. GOGOTSI, G. A., Deformational behavior of ceramics. J. Eur. Ceram. Soc., 7 (1991) 87-92.

3. SWAIN, M. V., Inelastic deformation of Mg-PSZ and its significe for strength-toughened relationship of zirconia toughned ceramics. Acta Metall., 33 (1985) 2083-2091.

4. TSUKUMA, K., Mechanical properties and thermal stability of $\mathrm{CeO}_{2}$ containing tetrogonal zirconia polycrystals. Am. Ceram. Soc. Bull., 65 (1986) 1386-1389.

5. MARSHALL, D. B., Strength characteristics of transformation-toughened zirconia. J. Amer. Ceram. Soc., 69 (1986) 173-180.
6. GOGOTSI, G. A., GALENKO, V. I. \& OZERSKY, B. I., Fracture toughness and another characteristics of zirconia with ferric oxide. Refractories and Technical Ceramics, 2 (1996) 2-9.

7. QUINN, G. D., KUBLER, J. J. \& GETTINGS, R. J., Fracture toughness of advanced ceramics by the surface crack testing in flexure (SCF) methods. VAMAS Round Robin, Report No. 17. ISSN 10165, 1994.

8. VEITCH, S., MARSHAL, M. \& SWAIN, M. V., Strength and toughness of Mg-PSZ and Y-YZP materials in cryogenic temperatures. Adv. Struct. Ceram., Mater. Res. Soc., 78 (1987) 328-333.

9. GOGOTSI, G. A., LOMONOVA, E. E. \& PEJCHEV, V. G., Strength and fracture of zirconia crystals. J. Eur. Ceram. Soc., 11 (1993) 405-412.

10. GOGOTSI, G. A. \& GROUSHEVSKY, YA. L., Statistical studies of the strength of inelastic ceramics. Ceram. Int., 8 (1983) 22-26.

11. GOGOTSI, G. A., GALENKO, V. I., ZAVADA, V. P., OSTROVOY, D. YU. \& KABAJASHY, T., Fracture toughness evaluation of $\mathrm{ZrO}_{2}$ and $\mathrm{Si}_{3} \mathrm{~N}_{4}$ ceramics. Refractories and Technical Ceramics, 1 (1996) 21-26 (in Russian).

12. GOGOTSI, G. A., Test methods of advanced ceramicsreasonable approaches of certification of ceramics. Key Engineering Mater., 56-57 (1991) 419-434.

13. ASTM C116-90, Standard test method for flexural strength of advanced ceramics at ambient temperature. ASTM, Philadelphia, 1991.

14. NADAI, A., Theory of Flow and Fracture of Solids. McGraw-Hill, New York, 1980.

15. SRAWLEY, J. E., Wide-range stress intensity factor expression for E-399 standard fracture toughens specimens. Int. J. Fract., 12 (1976) 475-476.

16. CHANTICUL, P., ANTIS, G. R., LAUN, B. R. \& MARSHALL, D. B., A critical evaluation of indentation techniques for measuring fracture toughens: 2. Strength method. J. Am. Ceram. Soc., 64 (1981) 539-543.

17. MARShAL, D. B. \& EVANS, A. D., Reply to comment on elastic/plastic indentation damage in ceramics: the median/radial crack system. J. Am. Ceram. Soc., 64 (1981) 182-183.

18. NIIHARA, K., MORENA, R. \& HASSELMAN, D. P. H., Evaluation of $K_{1 c}$ of brittle solids by the indentation method with low crack-to indentation. J. Mater. Sci. Lett., 1 (1982) 13-15.

19. GOGOTSI, G. A., GALENKO, V. I., OZERSKY, B. I., LOMONOVA, E. E., MYSINA V. A., VISHNYAKOVA, M. A. \& KALABUCHOVA, V. F., Strength and crack resistance of zirconium dioxide crystals containing yttrium and terbium oxides. Refractories, 34 (1993) 303312 (transl. from Russian).

20. ASTM E-399, Standard test method for plane-strain fracture toughness of metallic materials. Annual Book of ASTM Standards, v. 03.01, ASTM, Philadelphia, 1991.

21. QUINN, G. D., SALEM, J., BAR-ON, I., CHO, K., FOLEY, M. \& FANG, H., Fracture toughness of advanced ceramics at room temperature. J. Res. Natl. Inst. Stand Technol., 97 (1992) 579-607.

22. JIS R 1607, Testing methods for fracture toughness of high performance ceramics. Japanese Standard Association, 1990.

23. GOGOTSI, G. A., ZAVADA, V. P. \& SWAIN, M. V., Mechanical properties characterization of $9 \mathrm{~mol} . \% \mathrm{Ce}-$ TZP ceramics material. 2. Fracture toughness. J. Eur. Ceram. Soc., 16 (1996) 347-357.

24. SMITH, S. M. \& SCATTERGOOD, R. O., Crack-shape effects for indentation fracture toughens measurements. J. Am. Ceram. Soc., 75 (1992) 539-554. 